Research Paper

\title{
Urinary UBC Rapid and NMP22 Test for Bladder Cancer Surveillance in Comparison to Urinary Cytology: Results from a Prospective Single-Center Study
}

Renate Pichler ${ }^{\bowtie}$, Gennadi Tulchiner ${ }^{1}$, Josef Fritz², Georg Schaefer ${ }^{3}$, Wolfgang Horninger ${ }^{1}$, Isabel Heidegger ${ }^{\boxplus}$

1. Department of Urology, Medical University of Innsbruck, Austria

2. Department of Medical Statistics, Informatics and Health Economics, Medical University of Innsbruck, Austria

3. Department of Pathology, Division of General Pathology, Medical University of Innsbruck, Austria

$\triangle$ Corresponding author: Renate Pichler, MD, PhD, FEBU and Isabel Heidegger, MD, PhD, FEBU. Medical University Innsbruck, Department of Urology. Anichstrasse 35, A-6020 Innsbruck, Austria. Email: Renate.Pichler@i-med.ac.at; Isabel-Maria.Heidegger@i-med.ac.at; Tel.: +43 (0) 51250424811 ; Fax: +43 (0) 512 50428365.

(c) Ivyspring International Publisher. This is an open access article distributed under the terms of the Creative Commons Attribution (CC BY-NC) license (https://creativecommons.org/licenses/by-nc/4.0/). See http://ivyspring.com/terms for full terms and conditions.

Received: 2017.03.05; Accepted: 2017.05.17; Published: 2017.07.19

\begin{abstract}
Background: Non-muscle invasive bladder cancer (NMIBC) is associated with high rates of recurrence, resulting in frequent follow-up cystoscopies. We evaluated the use of two point-of-care tests - the nuclear matrix protein 22 (NMP22) and urinary bladder cancer antigen (UBC) Rapid - compared to routine follow-up in patients with a previous history of NMIBC.

Methods: 31 patients with cystoscopy-verified active bladder cancer, and 44 follow-up patients without disease as confirmed by cystoscopy were prospectively enrolled. All urine samples were analyzed by voided urine and bladder washing cytology, NMP22 and UBC rapid test (qualitatively and quantitatively). The best cutoff (highest Youden index; $\geq 6.7 \mathrm{ng} / \mathrm{ml}$ ) for the quantitative UBC was determined by receiver operating characteristic curves.

Results: Voided urine and barbotage cytology resulted in a sensitivity of $25.8 \%$ and $32.3 \%$, and a specificity of $100 \%$ and $100 \%$, while the NMP22 showed a sensitivity and specificity of $12.9 \%$ and $100 \%$, respectively. The qualitative and quantitative UBC Rapid revealed a sensitivity of $61.3 \%$ and $64.5 \%$, with a specificity of $77.3 \%$ and $81.8 \%$. Barbotage cytology and qualitative UBC test proved to be the best dual combination with the highest overall sensitivity $(77.4 \%)$. In contrast to barbotage cytology alone, sensitivity increased from $21.4 \%$ to $50 \%$ for detecting low-grade tumors, and from $43.8 \%$ to $100 \%$ for high-grade cancers, but reducing specificity from $100 \%$ to $77.3 \%$.

Conclusion: Compared to urinary cytology, UBC tests alone as well as UBC tests in combination with bladder washing cytology revealed higher sensitivities in detecting low- and high-grade tumors, but at the expense of a lower specificity. Thus, currently cystoscopy cannot be replaced by any of the evaluated methods.
\end{abstract}

Key words: Bladder Cancer; surveillance; recurrence; urine markers; cytology; NMP22; UBC; biomarkers

\section{Introduction}

Bladder cancer (BCa) is the eleventh most commonly diagnosed cancer in the world with an estimated 430000 new cases reported in 2012. It also ranks fourteenth among the leading causes of cancer death [1-2]. Given the steadily rising life expectancy and the rising costs of health care systems, BCa has become a global problem [1-2]. For example, bladder cancer caused an expense of about 2.9 billion Euros 
for public health systems across the European Union in 2012, constituting $5 \%$ of the total health care expenses for cancer [3].

At the initial diagnosis, as many as $75 \%$ of patients with $\mathrm{BCa}$ present with non-muscle invasive disease confined to the mucosa or submucosa [4]. The majority of patients in this stage of disease are successfully treated with endoscopic surgery, followed by adjuvant intravesical chemotherapy or Bacillus-Calmette Guérin (BCG) instillation treatment in the case of intermediate-risk and high-risk non-muscle invasive bladder cancer (NMIBC), [5]. Non-muscle invasive cancer disease has a significant lower risk of cancer-specific mortality with a better long-term survival compared to muscle-invasive bladder cancer $[4,6]$. Nevertheless, lifelong follow-up is needed in non-muscle invasive disease because of the high probability of recurrence (ranging from 15\% to $61 \%$ at 1 year and from $31 \%$ to $78 \%$ at 5 years), especially in patients with carcinoma in situ (CIS) and T1 lesions with a high potential for malignancy $[5,7]$. Thus, surveillance of NMIBC should be risk-adapted, with regular cystoscopies, urinary cytology and upper urinary tract imaging in the follow-up recommendation of current guidelines [8-9].

Cytopathology of the voided bladder or bladder washing urine specimens is a widely used and non-invasive test for the detection or in the surveillance of bladder cancer, with a high sensitivity of $84 \%$ in high-grade BCa [10-11]. Although cytology is very specific (about 86\%), its overall low sensitivity $(48 \%)$ is a clear limitation. In fact, its sensitivity is a mere $16 \%$ for low-grade tumors [10-11]. Moreover, the diagnostic accuracy of urinary cytology varies between study centers because of subjective cytology interpretation criteria, depending on the expertise and experience of cytopathologists requiring highly trained healthcare professionals, who may not be available in all areas [11-12]. Over the years, various classification schemes for urinary cytology have been published, introducing the Paris System for Reporting Urine Cytology in 2013 [13-14]. Some limitations of prior classification schemes include a lack of rigorous definition of validated cytological criteria for individual categories and a lack of consensus for atypical categorization [14]. Hence, significant efforts have been made to develop novel molecular and gene-based urinary tests that may reduce or, ideally replace, the frequency of endoscopy in patients under surveillance for BCa recurrence [15].

The aim of this prospective study was to evaluate and compare the diagnostic accuracy of urinary cytology (voided urine and bladder washing) with two urine-based point-of-care (POC) tests - the nuclear matrix protein $22(\mathrm{NMP} 22){ }^{\circledR}$ BladderChek and the urinary bladder cancer antigen $(\mathrm{UBC})^{\circledR}$ rapid (qualitative and quantitative) test - for the surveillance of patients with a previous history of non-muscle invasive bladder cancer (NMIBC).

\section{Material and Methods}

This prospective single-center study was approved by the local ethics committee (study number AN2016-0056; 360/4.7) of the Medical University of Innsbruck (Austria). Informed written consent for further urine analysis in addition to standard urine cytology was obtained from each patient prior to inclusion in the study. Patients with a previous history of NMIBC who had undergone routine oncological follow-up at our outpatient uro-oncology department between May 2016 and September 2016 were enrolled prospectively in the pilot study. To exclude a urinary tract infection, all patients underwent a routine urine dipstick analysis prior to cystoscopy. Symptomatic bacteriuria or a florid urinary tract infection was a contraindication for further investigation, and thus an exclusion criterion for the study.

The follow-up protocol included cystoscopy (flexible in men, rigid in women) in combination with voided urine and bladder washing cytology as the gold standard. In addition, all urinary samples were analyzed with two POC tests: the $\mathrm{NMP} 22^{\circledR}$ BladderChek and the UBC ${ }^{\circledR}$ Rapid test (visually and quantitatively by the Omega 100 POC reader). The frequency of cystoscopy during follow-up depended on tumor histology and tumor grading. In accordance with the current European Association of Urology (EAU) guidelines and our institutional practice, patients with low-risk NMIBC underwent a cystoscopy every 3 months during the first year, and then once a year for 5 years. Intermediate-risk and high-risk NMIBC were followed by cystoscopy every 3 months during the first two years, at 6-month intervals for 5 years, and then once a year [8]. Upper urinary tract imaging (CT-urography) was carried out once a year in high-risk NMIBC (according to the European Organization for Research and Treatment of Cancer scoring system and risk tables [5]) or when a disease recurrence was detected. In case of cystoscopyverified cancer recurrence or a positive cytology with no visible tumor, transurethral resection of the bladder (TURB) or PDD-guided, random-biopsies were performed. All cancer specimens obtained from TURB were investigated in regard of diagnosis, tumor grade (WHO 1973 and 2004) and stage (TNM 2009) by an experienced uropathologist.

Cytological evaluation of urinary specimens for exfoliated tumor cells was performed according to the Papanicolaou scheme. While classes 1 and 2 were 
considered negative, classes 4 and 5 were deemed suspicious and positive for bladder cancer [14]. Patients with class 3 (atypical urothelial cells) cytological findings and negative cystoscopy underwent a cystoscopy and urine cytology control three months later.

The qualitative NMP22 ${ }^{\circledR}$ BladderChek test (Alere, Waltham, Massachusetts, USA) and the UBC® Rapid test (Concile, Freiburg im Breisgau, Germany) were performed according to the manufacturers' protocols. Briefly, the NMP22 enzyme immunoassay is specific for the nuclear mitotic apparatus protein (NuMA), an abundant component of the nuclear matrix protein, which can be overexpressed in the nucleus of different cancer cells where aneuploidy is a common feature in driving tumor progression (such as epithelian ovarian cancer [16]), reflecting mitotic activity of cells [17]. The UBC ${ }^{\circledR}$ Rapid test measures the soluble fragments of cytokeratin 8 and 18, which play an active role in tumor invasion [18], by qualitative determination, as well as quantitatively using the Omega 100 POC reader (Concile, Freiburg im Breisgau, Germany).

\section{Statistics}

For the assessment of the diagnostic accuracy of voided urine and bladder wash cytology, NMP22 BladderChek ${ }^{\circledR}$ test, and qualitative UBC Rapid ${ }^{\circledR}$ test as compared to cystoscopy, data were tabulated in contingency tables. Sensitivity, specificity, positive and negative predictive values (PPV and NPV) were calculated. These analyses were also performed after stratification by tumor grade and tumor stage. For all tests, receiver operating characteristic (ROC) curves were plotted and the area under the curve (AUC) was calculated and tested for significance with the MannWhitney-U test. The optimal cutoff value for the quantitative UBC Rapid ${ }^{\circledR}$ test was determined as the value with the highest Youden index. To determine whether the combination of any two or more of the qualitative tests improves the diagnostic accuracy, we compared the sensitivity, specificity, positive and negative predictive value, and AUCs of various combined tests (deemed positive when any of the single tests yielded a positive result, otherwise negative) against the single test results. A significance level of a $=0.05$ (two-tailed) was applied for all p-values. Statistical analyses were performed using the SPSS software, version 22 (IBM Corp., Armonk, NY).

\section{Results}

\section{Baseline characteristics}

In all 75 patients [21 (28.0\%) women and 54 $(72.0 \%)$ men] with a mean age of 70.6 years (median 70 , range 38-91 years) were enrolled in this prospective study. All patients underwent a routine follow-up of a previous NMIBC. Tumor recurrence was noted in $31(41.3 \%)$ of 75 patients, respectively. Histological investigation of TURB confirmed pTa, carcinoma in situ (CIS), pT1 and pT2 in 16 (51.6\%), 6 $(19.4 \%), 6(19.4 \%)$ and $3(9.6 \%)$ patients, respectively. Fifteen $(48.4 \%)$ and $16(51.6 \%)$ were classified as low-grade and high-grade tumors, respectively, according to the $2004 \mathrm{WHO}$ classification system. Grades 1, 2, 3 were identified in 10 (32.3\%), 9 (29\%) and $12(38.7 \%)$ tumors, respectively, based on the 1973 WHO classification.

\section{Diagnostic accuracy of urinary cytology, the NMP22, the qualitative and the quantitative UBC Rapid test as single tests}

The sensitivities, specificities, PPVs and NPVs of the individual tests for predicting bladder cancer recurrence are shown in Table 1 . ROC curves and AUCs for cytology (voided urine and bladder wash), NMP22, quantitative and qualitative UBC test are summarized in Figures 1A-1E, Figures 1G-1H.

Urinary cytology of voided urine and bladder washing yielded an overall sensitivity, specificity, PPV and NPV of $25.8 \%$ and $32.3 \%, 100 \%$ and $100 \%$, $100 \%$ and $100 \%$, and 65.2 and $67.7 \%$, respectively. The AUC after ROC analysis was 0.63 for voided urine cytology $(p=0.060)$, and $0.66(p=0.018)$ for barbotage cytology. The calculated sensitivity of cytology (voided urine and bladder wash) was both $43.8 \%$ for high-grade tumors, but only $7.1 \%$ and $21.4 \%$ for low-grade tumors. The highest sensitivity was achieved for primary CIS $(66.7 \%$ for voided and barbotage cytology) and pT2 tumors (66.7\% for both, voided and bladder wash cytology).

The NMP22 BladderChek ${ }^{\circledR}$ test showed a low sensitivity of $12.9 \%$ and a high specificity of $100 \%$; PPV and NPV were $100 \%$ and $61.9 \%$, respectively. The AUC was 0.56 , with no significant ability to predict tumor recurrence $(p=0.344)$. The sensitivity of the NMP22 test for detecting low-grade and high-grade tumors was $7.1 \%$ and $18.8 \%$, respectively.

The overall sensitivity, specificity, PPV and NPV of the visually (strong band intensity= positive) evaluated qualitative $\mathrm{UBC}^{\circledR}$ Rapid test was $61.3 \%$, $77.3 \%, 65.5 \%$ and $73.9 \%$, respectively. The sensitivity increased with tumor grade (low-grade vs. high-grade, $28.6 \%$ vs. $87.5 \%$ ) and tumor stage (pTa vs. pT2, $37.5 \%$ vs. $66.7 \%$ ).

For the quantitative $\mathrm{UBC}^{\circledR}$ Rapid test using the optimal threshold obtained by ROC analysis (cutoff $\geq$ $6.7 \mathrm{ng} / \mathrm{ml}$ ), the sensitivity, specificity, PPV and NPV were $64.5 \%, 81.8 \%, 71.4 \%$ and $76.6 \%$, respectively. This urinary POC test yielded the highest AUC value $(0.75 ; p<0.001)$. 
Table 1. Diagnostic accuracy including sensitivity, specificity, PPV and NPV for each single urinary marker such as NMP22 ${ }^{\circledR}$ BladderChek, qualitative and quantitative (using the best cutoff of $6.7 \mathrm{ng} / \mathrm{ml}$ ) UBC ${ }^{\circledR}$ Rapid test, and urine cytology (voided urine and bladder wash). Sensitivities were stratified by tumor grade and tumor stage.

\begin{tabular}{|c|c|c|c|c|c|c|}
\hline & $\begin{array}{l}\text { Sensitivity } \\
(\%)\end{array}$ & $\begin{array}{l}\text { Specificity } \\
(\%)\end{array}$ & $\begin{array}{l}\text { PPV } \\
(\%)\end{array}$ & $\begin{array}{l}\text { NPV } \\
(\%)\end{array}$ & $\begin{array}{l}\text { AUC } \\
(95 \% \text { CI })\end{array}$ & P-value* \\
\hline NMP22 & 12.9 & 100.0 & 100.0 & 61.9 & 0.56 & 0.344 \\
\hline Low-grade & 7.1 & & & & $(0.43-0.70)$ & \\
\hline High-grade & 18.8 & & & & & \\
\hline pTa & 6.3 & & & & & \\
\hline CIS & 16.7 & & & & & \\
\hline pT1 & 40.0 & & & & & \\
\hline pT2 & 0.0 & & & & & \\
\hline UBC qualitative & 61.3 & 77.3 & 65.5 & 73.9 & 0.69 & 0.005 \\
\hline Low-grade & 28.6 & & & & $(0.57-0.82)$ & \\
\hline High-grade & 87.5 & & & & & \\
\hline pTa & 37.5 & & & & & \\
\hline CIS & 83.3 & & & & & \\
\hline pT1 & 100.0 & & & & & \\
\hline pT2 & 66.7 & & & & & \\
\hline $\begin{array}{l}\text { UBC quantitative } \\
\text { (best cutoff }>6.7 \\
\mathrm{ng} / \mathrm{mL} \text { ) }\end{array}$ & 64.5 & 81.8 & 71.4 & 76.6 & $\begin{array}{l}0.75 \\
(0.64-0.87)\end{array}$ & $<0.001$ \\
\hline Low-grade & 35.7 & & & & & \\
\hline High-grade & 87.5 & & & & & \\
\hline pTa & 37.5 & & & & & \\
\hline CIS & 100.0 & & & & & \\
\hline pT1 & 100.0 & & & & & \\
\hline pT2 & 66.7 & & & & & \\
\hline $\begin{array}{l}\text { Urinary cytology } \\
\text { (voided urine) }\end{array}$ & 25.8 & 100.0 & 100.0 & 65.2 & $\begin{array}{l}0.63 \\
(0.49-0.76)\end{array}$ & 0.060 \\
\hline Low-grade & 7.1 & & & & & \\
\hline High-grade & 43.8 & & & & & \\
\hline pTa & 6.3 & & & & & \\
\hline CIS & 66.7 & & & & & \\
\hline pT1 & 20.0 & & & & & \\
\hline pT2 & 66.7 & & & & & \\
\hline $\begin{array}{l}\text { Urinary cytology } \\
\text { (bladder washing) }\end{array}$ & 32.3 & 100.0 & 100.0 & 67.7 & $\begin{array}{l}0.66 \\
(0.53-0.79)\end{array}$ & 0.018 \\
\hline Low-grade & 21.4 & & & & & \\
\hline High-grade & 43.8 & & & & & \\
\hline pTa & 18.8 & & & & & \\
\hline CIS & 66.7 & & & & & \\
\hline pT1 & 20.0 & & & & & \\
\hline pT2 & 66.7 & & & & & \\
\hline
\end{tabular}

The positive predictive value of the quantitative UBC Rapid test for bladder cancer and high-grade bladder cancer was strongly correlated with increaseing cutoffs, Figure 1F. Specifically, the PPV (95\% CI) of bladder cancer increased from $72.0 \%$ (58.1\%-86.4\%; cutoff $\geq 6.7 \mathrm{ng} / \mathrm{ml}), 73.1 \%$ (56.3\%-89.5\%; cutoff $\geq 10$ $\mathrm{ng} / \mathrm{ml}), 75 \%$ (53.9-93.8\%; cutoff $\geq 15 \mathrm{ng} / \mathrm{ml}), 75 \%$ (50.0\%-100\%; cutoff $\geq 20 \mathrm{ng} / \mathrm{ml})$ to $87.5 \%$ ( $50.0 \%-100 \%$; cutoff $\geq 40 \mathrm{ng} / \mathrm{ml})$. For high-grade BCa, the PPV was $51.9 \%(40.0 \%-66.7 \%)$ for a cutoff of $\geq 6.7 \mathrm{ng} / \mathrm{ml}, 57.9 \%$ (42.9\%-76.5\%) for $\geq 10 \mathrm{ng} / \mathrm{ml}, 62.5 \%$ (42.9\%-83.3\%) for $\geq 15 \mathrm{ng} / \mathrm{ml}, 66.7 \%$ (42.9\%-90.9\%) for $\geq 20 \mathrm{ng} / \mathrm{ml}$ and $72.7 \%(37.5 \%-100 \%)$ for a threshold of $\geq 40 \mathrm{ng} / \mathrm{ml}$, Figure 1F.
Diagnostic accuracy for different combinations of urinary cytology with the NMP22, the quantitative and qualitative UBC Rapid test

Table 2 shows the results obtained by combining the individual diagnostic methods. Combining each urinary POC marker test with urinary cytology, barbotage cytology and the qualitative UBC Rapid test proved to be the best dual combination with the highest sensitivity $(77.4 \%)$ and AUC value $(0.77 ; 95 \%$ CI: 0.66-0.88). In contrast to bladder wash cytology alone, the sensitivity for the combination of barbotage cytology and the qualitative UBC for detecting low-grade and high-grade tumors increased from $21.4 \%$ to $50.0 \%$ and from $43.8 \%$ to $100 \%$, but reducing specificity from $100 \%$ to $77.3 \%$ (Figure 1G and Table 2). Performing a triple combination, bladder wash cytology, the qualitative UBC Rapid and the NMP22 test resulted in a sensitivity, specificity, PPV and NPV of $80.6 \%, 77.3 \%, 71.4 \%$ and $85 \%$, respectively (Figure 1H and Table 2).

\section{Discussion}

In view of the fact that urinary cytology is of limited diagnostic value for detecting low-grade bladder tumors (in our series the sensitivity of bladder wash cytology was $21.4 \%$ ) compared to high-grade tumors (up to 84\% [10]), novel molecular and gene-based urinary tests are currently being developed and tested, partially in clinical practice, with promising preliminary results [19-20]. One example is a urinary assay combination of FGF3, TERT and OTX1, with a sensitivity of $57 \%$ for the detection of low-grade NMIBC, $83 \%$ for pT1 tumors and $72 \%$ for high-grade disease [21]. Despite a negative cystoscopy, positive urinary test results were predictive of recurrence over time, in comparison to negative urine samples (58\% vs. 36\%), [21]. Moreover, urinary miRNA analysis also seems to be a valuable method for the BCa surveillance [22]. A urinary miRNA panel including six miRNAs detected cancer recurrence with a high sensitivity of $84.8 \%$ [22] to $88 \%$ [20], thus reducing cystoscopy rates by $30 \%$ in the validation cohort [20]. However, the "ideal urine-based marker" for detecting BCa recurrence during surveillance would be rapid, noninvasive, easy to perform and interpret, and must possess not only a high specificity to reduce superfluous cystoscopies on oncological follow-up, but also a high sensitivity so that no patient with low-grade and high-grade bladder cancer will be missed [12]. Nevertheless, there is a paucity of randomized trials concerning urinary molecular marker tests for evaluating the possibility of safely reducing cystoscopy rates during surveillance. 

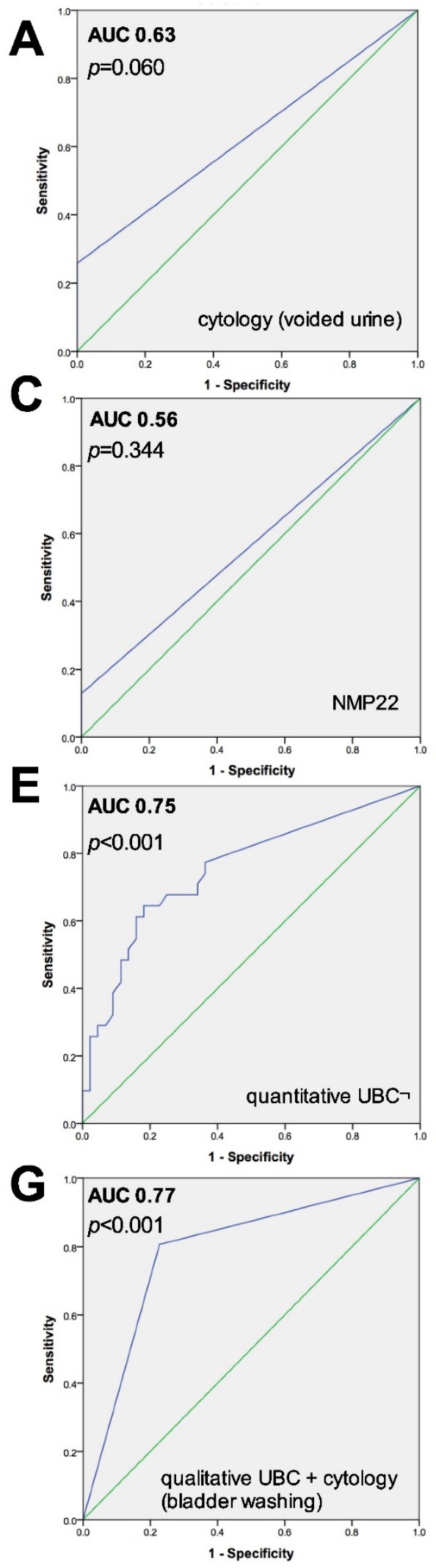

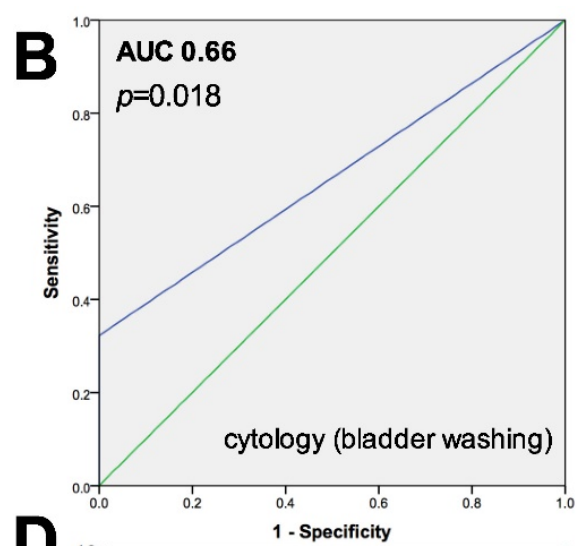

D

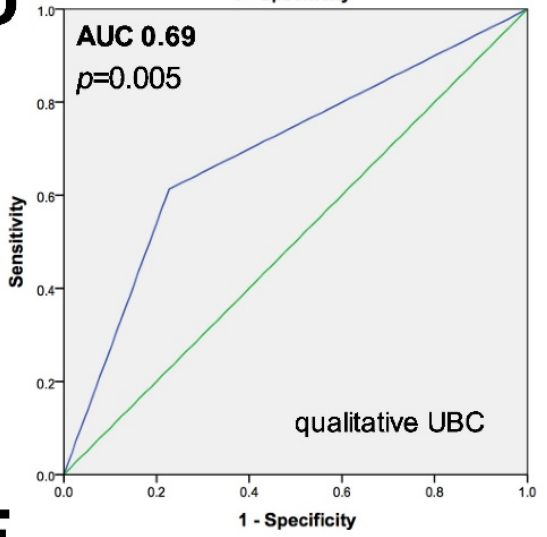

$\mathbf{F}$

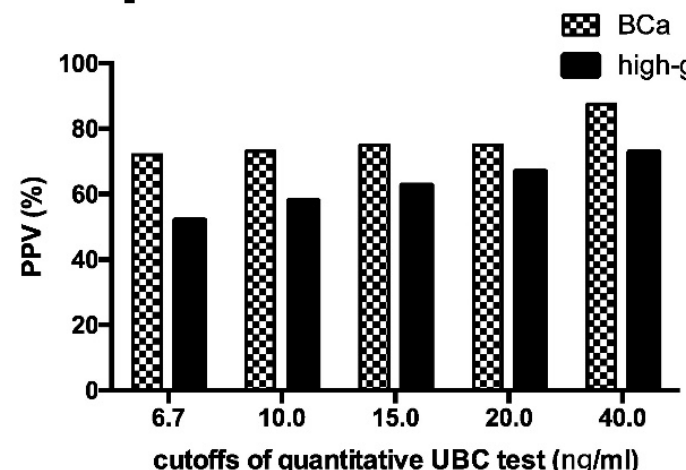

(n) $(\mathrm{ng} / \mathrm{ml})$

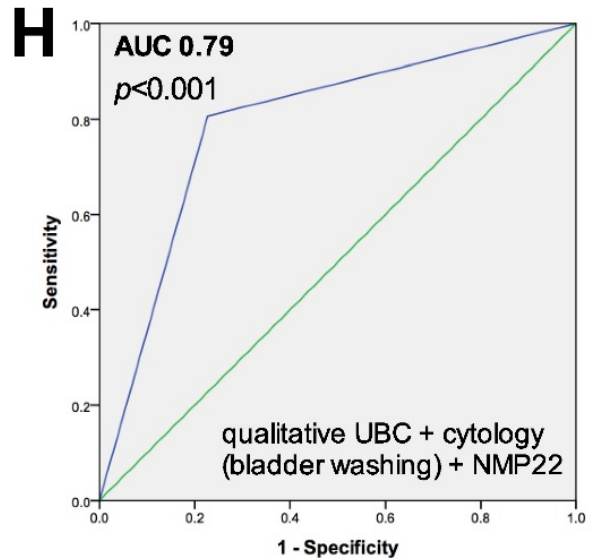

Figure 1. A-E, G-H) ROC curves and AUC calculated for voided and barbotage cytology, NMP22 test, quantitative and qualitative UBC test as single investigations, and different combinations. F) Positive predictive value (PPV) of the quantitative UBC test in percentages (\%), based on different cutoffs, concerning the probability of bladder cancer $(\mathrm{BCa})$ and high-grade $\mathrm{BCa}$. 
Table 2. Diagnostic accuracy including sensitivity, specificity, PPV and NPV for different combinations of NMP22 ${ }^{\circledR}$ BladderChek, qualitative and quantitative (using the best cutoff of $6.7 \mathrm{ng} / \mathrm{ml}$ ) UBC ${ }^{\circledR}$ Rapid test, and urine cytology (voided urine and bladder wash). Sensitivities were stratified by tumor grade and tumor stage.

\begin{tabular}{|c|c|c|c|c|c|c|}
\hline & Sensitivity $(\%)$ & Specificity $(\%)$ & PPV (\%) & NPV (\%) & AUC (95\% CI) & P-value \\
\hline NMP22 + cytology (voided urine) & 32.3 & 100.0 & 100.0 & 67.2 & 0.66 & 0.018 \\
\hline Low-grade & 14.3 & & & & $(0.53-0.79)$ & \\
\hline High-grade & 50.0 & & & & & \\
\hline pTa & 12.5 & & & & & \\
\hline CIS & 66.7 & & & & & \\
\hline pT1 & 40.0 & & & & & \\
\hline pT2 & 0.0 & & & & & \\
\hline NMP22 + cytology (bladder washing) & 38.7 & 100.0 & 100.0 & 69.8 & 0.69 & 0.005 \\
\hline Low-grade & 28.6 & & & & $(0.56-0.82)$ & \\
\hline High-grade & 50.0 & & & & & \\
\hline pTa & 25.0 & & & & & \\
\hline CIS & 66.7 & & & & & \\
\hline pT1 & 40.0 & & & & & \\
\hline pT2 & 66.7 & & & & & \\
\hline UBC qualitative + cytology (voided urine) & 71.0 & 76.7 & 68.8 & 78.6 & 0.74 & $<0.001$ \\
\hline Low-grade & 35.7 & & & & $(0.62-0.85)$ & \\
\hline High-grade & 100.0 & & & & & \\
\hline pTa & 43.8 & & & & & \\
\hline CIS & 100.0 & & & & & \\
\hline pT1 & 100.0 & & & & & \\
\hline pT2 & 0.0 & & & & & \\
\hline UBC qualitative + cytology (bladder washing) & 77.4 & 77.3 & 70.6 & 82.9 & 0.77 & $<0.001$ \\
\hline Low-grade & 50.0 & & & & $(0.66-0.88)$ & \\
\hline High-grade & 100.0 & & & & & \\
\hline pTa & 56.3 & & & & & \\
\hline CIS & 100.0 & & & & & \\
\hline pT1 & 100.0 & & & & & \\
\hline pT2 & 100.0 & & & & & \\
\hline NMP22 + UBC qualitative + cytology (voided urine) & 74.2 & 76.7 & 69.7 & 80.5 & 0.75 & $<0.001$ \\
\hline Low-grade & 42.9 & & & & $(0.64-0.87)$ & \\
\hline High-grade & 100.0 & & & & & \\
\hline pTa & 50.0 & & & & & \\
\hline CIS & 100.0 & & & & & \\
\hline pT1 & 100.0 & & & & & \\
\hline pT2 & 0.0 & & & & & \\
\hline $\begin{array}{l}\text { NMP22 + UBC qualitative + cytology (bladder } \\
\text { washing) }\end{array}$ & 80.6 & 77.3 & 71.4 & 85.0 & $\begin{array}{l}0.79 \\
(0.68-0.89)\end{array}$ & $<0.001$ \\
\hline Low-grade & 57.1 & & & & & \\
\hline High-grade & 100.0 & & & & & \\
\hline $\mathrm{pTa}$ & 62.5 & & & & & \\
\hline CIS & 100.0 & & & & & \\
\hline pT1 & 100.0 & & & & & \\
\hline pT2 & 0.0 & & & & & \\
\hline UBC quantitative + cytology (voided urine) & 71.0 & 81.4 & 73.3 & 79.5 & 0.76 & $<0.001$ \\
\hline Low-grade & 42.9 & & & & $(0.64-0.88)$ & \\
\hline High-grade & 93.8 & & & & & \\
\hline $\mathrm{pTa}$ & 43.8 & & & & & \\
\hline CIS & 100.0 & & & & & \\
\hline pT1 & 100.0 & & & & & \\
\hline pT2 & 0.0 & & & & & \\
\hline UBC quantitative + cytology (bladder washing) & 74.2 & 81.8 & 74.2 & 81.8 & 0.78 & $<0.001$ \\
\hline Low-grade & 50.0 & & & & $(0.67-0.89)$ & \\
\hline High-grade & 93.8 & & & & & \\
\hline pTa & 50.0 & & & & & \\
\hline CIS & 100.0 & & & & & \\
\hline pT1 & 100.0 & & & & & \\
\hline pT2 & 0.0 & & & & & \\
\hline UBC quantitative + NMP22 + cytology (voided urine) & 74.2 & 81.4 & 74.2 & 81.4 & 0.78 & $<0.001$ \\
\hline Low-grade & 50.0 & & & & $(0.66-0.89)$ & \\
\hline High-grade & 93.8 & & & & & \\
\hline pTa & 50.0 & & & & & \\
\hline CIS & 100.0 & & & & & \\
\hline pT1 & 100.0 & & & & & \\
\hline pT2 & 0.0 & & & & & \\
\hline $\begin{array}{l}\text { UBC quantitative + NMP22 + cytology (bladder } \\
\text { washing) }\end{array}$ & 77.4 & 81.8 & 75.0 & 83.7 & $\begin{array}{l}0.79 \\
(0.69-0.90)\end{array}$ & $<0.001$ \\
\hline Low-grade & 57.1 & & & & & \\
\hline High-grade & 93.8 & & & & & \\
\hline pTa & 56.3 & & & & & \\
\hline CIS & 100.0 & & & & & \\
\hline pT1 & 100.0 & & & & & \\
\hline pT2 & 0.0 & & & & & \\
\hline
\end{tabular}


In this prospective study, we investigated the diagnostic value of two urinary-based POC tests (NMP22 BladderChek ${ }^{\circledR}$ and UBC Rapid ${ }^{\circledR}$ ) versus urine cytology for the detection of $\mathrm{BCa}$ recurrence in the surveillance of patients with a previous history of NMIBC. A variety of urinary POC test systems are available on the market at the present time, permitting non-invasive and rapid determination of urinary markers, but their diagnostic accuracy is controversially discussed in a limited number of studies [23-24]. The sensitivities are usually higher than those reported for urinary cytology alone, but at the cost of a lower specificity [15,24]. Thus, the additional costs of further urinary markers in the surveillance protocol are not justified at the moment [25]. The use of those markers for routine follow-up is not recommended in clinical practice by current guidelines, and remains a debated issue $[8,24]$. Urinary tract infection, previous intravesical BCG or chemotherapy instillation therapy, mechanical stress due to instrumented urine sampling, benign conditions or hematuria (especially for the BTA stat test) were noted in connection with many urinary marker tests, resulting in frequent false positive results $[15,24,26-28]$. Another limitation of the tests is the fact that they only permit a qualitative analysis, because they yield a simple positive or negative result. The overall sensitivity and specificity of the qualitative NMP22 BladderChek ${ }^{\circledR}$ test for detecting $\mathrm{BCa}$ recurrence has been reported to range from $16.4 \%$ to $55.7 \%$, and $85.7 \%$ to $100 \%$, respectively [29-31]. These results are in line with our findings, which yielded a low overall sensitivity of $12.9 \%$ and a high specificity of $100 \%$ for the NMP22 test, and a similar low sensitivity when stratified by tumor grade $(7.1 \%$ for low-grade and $18.8 \%$ high-grade tumors). Consequently, the NMP22 test did not significantly improve the diagnostic accuracy of urinary barbotage cytology alone $(21.4 \%$ and $43.8 \%$ for low-grade and high-grade) compared to the combined assessment (NMP22 plus barbotage cytology: $28.6 \%$ and $50.0 \%$ ).

For the urinary $\mathrm{BC}$ antigen (UBC) Rapid ${ }^{\circledR}$ test, the Concile Omega 100 reader was developed to obtain quantitative data in addition to the qualitative analysis [31]. The sensitivity of the qualitative UBC Rapid test ranged from from $46.2 \%$ to $78.4 \%$, and its specificity from $82.4 \%$ to $97.4 \%$ [31-36]. These data concur with our own, which revealed an overall sensitivity and specificity of $61.3 \%$ and $77.3 \%$, respectively. Whereas the sensitivity was low (28.6\%) for detecting low-grade tumors, it increased to $87.5 \%$ for high-grade tumors and achieved the highest sensitivity of a single urinary marker test for detecting high-grade BCa.

Combined application of urinary cytology and molecular urine markers such as fluorescence in situ hybridization (FISH) or immunocytology $(\mathrm{uCyt}+)$ could improve the diagnostic accuracy of detecting BCa compared to cytology alone [37-38]. We observed the highest overall sensitivity of $77.4 \%$ (AUC $=0.77$ ) for the dual combination of the qualitative UBC Rapid ${ }^{\circledR}$ test and bladder washing cytology, increasing the sensitivity for low-grade and high-grade tumors from $21.4 \%$ to $50 \%$, and from $43.8 \%$ to $100 \%$, compared to bladder washing cytology alone.

The diagnostic accuracy of the the quantitative $\mathrm{UBC}^{\circledR}$ Rapid POC system has been assessed in just four studies, which reported a sensitivity of $46.6 \%$ to $64.5 \%$ and a specificity ranging from $70.1 \%$ to $86.3 \%$, respectively [31-32, 35-36]. In our series, the quantitative UBC test using the best cutoff (highest Youden index) of $\geq 6.7 \mathrm{ng} / \mathrm{ml}$ showed the highest overall sensitivity and specificity of $64.5 \%$ and $81.8 \%$, respectively, for a single urine marker test. Moreover, the probability of detecting $\mathrm{BCa}$ as well as high-risk BCa clearly increased with the cutoff value of the UBC rapid test [31]. The PPV of the quantitative UBC was $42.7 \%$ and $21.9 \%$ for detecting $\mathrm{BCa}$ and high-risk tumors using a UBC concentration $>10 \mathrm{ng} / \mathrm{ml}$, and increased to $75 \%$ and $55 \%$ for a UBC concentration $>60 \mathrm{ng} / \mathrm{ml}$ [31]. This fact was confirmed in our study: we noted a PPV (95\% CI) of 73.1\% (56.3-89.5\%) for detecting BCa using $10 \mathrm{ng} / \mathrm{ml}$ as a cutoff, and $87.5 \%$ $(50-100 \%)$ for $\geq 40 \mathrm{ng} / \mathrm{ml}$. For high-grade tumors, the PPV increased from $57.9 \%(42.9-76.5 \%)$ to $72.7 \%$ (37.5-100\%), compared to the threshold of $\geq 10 \mathrm{ng} / \mathrm{ml}$ and $\geq 40 \mathrm{ng} / \mathrm{ml}$. Nevertheless, neither quantitative UBC alone (sensitivity 35.7\%) nor its combination with bladder washing cytology (sensitivity 50.0\%) was sufficiently sensitive for detecting low-grade bladder cancers compared to high-grade tumors $(87.5 \%$ and $93.8 \%)$, with a reduction of specificity from $100 \%$ to $81.4 \%$ using a dual combination (quantitative UBC and barbotage cytology).

The main limitation of this single-center pilot study is the small sample size of 75 patients, which limited the statistical interpretation with its quality and reproducibility as well. The merits of the investigation are worthy of mention: it was a prospective assessment of a homogeneous patient population with a previous history of NMIBC using a standardized oncological surveillance protocol including cystoscopy, voided urine and bladder washing cytology, with routine upper urinary tract imaging performed once a year in high-risk NMIBC patients and in all patients with cancer recurrence.

\section{Conclusion}

The overall sensitivity of both, the qualitative and the quantitative UBC Rapid test was higher, but 
its specificity was lower than that of urinary cytology alone, whereas the sensitivity of the qualitative NMP22 test remained consistently lower. The sensitivity for detecting low-grade tumors was similarly low in all analyzed single urinary molecular test methods (between $7.1 \%$ and 35.7\%). The best dual combination of test methods with the highest overall sensitivity of $77.4 \%$ was achieved through the qualitative UBC Rapid test and bladder wash cytology. It revealed high-grade cancers in $100 \%$, but low-grade tumors with a sensitivity of $50.0 \%$, with a reduction of specificity from $100 \%$ to $77.3 \%$. Based on these data, none of the assessed urinary marker tests alone or any combinations of these a) meets all of the criteria of an "ideal urine tumor marker" and thus, b) can currently replace cystoscopy for oncological BCa surveillance.

\section{Abbreviations}

AUC, area under the curve; $\mathrm{BCa}$, bladder cancer; CIS, carcinoma in situ; NMIBC, non-muscle invasive bladder cancer; NMP22, nuclear matrix protein 22; NPV, negative predictive value; NuMA, nuclear mitotic apparatus protein; POC, point of care; PPV, positive predictive value; $\mathrm{ROC}$, receiver operating curve; TURB, transurethral resection of the bladder; $\mathrm{UBC}$, urinary bladder cancer antigen.

\section{Acknowledgments}

We thank Werner Uhl-Michelin of In Vitro Diagnostika for supporting this work, by providing the Omega 100 POC reader free of charge for this pilot study.

\section{Competing interests} interest.

The authors declare that there are no conflicts of

\section{References}

1. Antoni S, Ferlay J, Soerjomataram I, Znaor A, Jemal A, Bray F. Bladder Cancer Incidence and Mortality: A Global Overview and Recent Trends. Eur Urol. 2016 Jun 28. pii: S0302-2838(16)30280-9. doi: 10.1016/j.eururo.2016.06.010.

2. Ferlay J, Shin HR, Bray F, Forman D, Mathers C, Parkin DM. Estimates of worldwide burden of cancer in 2008: GLOBOCAN 2008. Int J Cancer. 2010 Dec 15;127(12):2893-917. doi: 10.1002/ijc.25516.

3. Leal J, Luengo-Fernandez R, Sullivan R, Witjes JA. Economic Burden of Bladder Cancer Across the European Union. Eur Urol. 2016 Mar;69(3):438-47. doi: 10.1016/j.eururo.2015.10.024.

4. Burger M, Catto JW, Dalbagni G, et al. Epidemiology and risk factors of urothelial bladder cancer. Eur Urol. 2013 Feb;63(2):234-41. doi: 10.1016/j.eururo.2012.07.033.

5. Sylvester RJ, van der Meijden AP, Oosterlinck W, et al. Predicting recurrence and progression in individual patients with stage Ta, T1 bladder cancer using EORTC risk tables: a combined analysis of 2596 patients from seven EORTC trials. Eur Urol 2006; 49(3):466-5.

6. Steinmaus C, Ferreccio C, Acevedo J, et al. Increased lung and bladder cancer incidence in adults after in utero and early-life arsenic exposure. Cancer Epidemiol Biomarkers prev 2014 Aug;23(8):1529-38.

7. Soukup V, Babjuk M, Bellmunt J, et al. Follow-up after surgical treatment of bladder cancer: a critical analysis of the literature. Eur Urol 2012 Aug;62(2):290-302
8. Babjuk M, Böhle A, Burger M, et al. EAU Guidelines on Non-Muscle-invasive Urothelial Carcinoma of the Bladder: Update 2016. Eur Urol. 2016 Jun 17. pii: S0302-2838(16)30249-4. doi: 10.1016/j.eururo.2016.05.041.

9. Kassouf W, Traboulsi SL, Schmitz-Dräger B, et al. Follow-up in non-muscle-invasive bladder cancer-International Bladder Cancer Network recommendations. Urol Oncol. 2016 Oct;34(10):460-8. doi: 10.1016/j.urolonc.2016.05.028

10. Yafi FA, Brimo F, Steinberg J, Aprikian AG, Tanguay S, Kassouf W. Prospective analysis of sensitivity and specificity of urinary cytology and other urinary biomarkers for bladder cancer. Urol Oncol. 2015 Feb;33(2):66.e25-31. doi: 10.1016/j.urolonc.2014.06.008.

11. Têtu B. Diagnosis of urothelial carcinoma from urine. Mod Pathol. 2009 Jun;22 Suppl 2:S53-9. doi: 10.1038/modpathol.2008.193.

12. Shariat SF, Karam JA, Lotan Y, Karakiewizc PI Critical evaluation of urinary markers for bladder cancer detection and monit oring. Rev Urol. 2008;10(2):120-35.

13. VandenBussche CJ. A review of the Paris system for reporting urinary cytology. Cytopathology. 2016 Jun;27(3):153-6. doi: 10.1111/cyt.12345.

14. Owens CL, Vandenbussche CJ, Burroughs FH, Rosenthal DL. A review of reporting systems and terminology for urine cytology. Cancer Cytopathol. 2013 Jan;121(1):9-14. doi: 10.1002/cncy.21253.

15. Lokeshwar VB, Habuchi T, Grossman HB, et al. Bladder tumor markers beyond cytology: International Consensus Panel on bladder tumor markers. Urology. 2005 Dec;66(6 Suppl 1):35-63.

16. Brüning-Richardson A, Bond J, Alsiary R, et al. NuMA overexpression in epithelial ovarian cancer. PLoS One. 2012;7(6):e38945. doi: 10.1371/journal.pone.0038945.

17. Zeng C. NuMA: a nuclear protein involved in mitotic centrosome function. Microsc Res Tech. 2000 Jun 1;49(5):467-77. Review.

18. Southgate J, Harnden P, Trejdosiewicz LK. Cytokeratin expression patterns in normal and malignant urothelium: a review of the biological and diagnostic implications. Histol Histopathol. 1999 Apr;14(2):657-64.

19. Sapre N, Anderson PD, Costello AJ, Hovens CM, Corcoran NM. Gene-based urinary biomarkers for bladder cancer: an unfulfilled promise? Urol Oncol. 2014 Jan;32(1):48.e9-17. doi: 10.1016/j.urolonc.2013.07.002

20. Sapre N, Macintyre G, Clarkson M, et al. A urinary microRNA signature can predict the presence of bladder urothelial carcinoma in patients undergoing surveillance. Br J Cancer. 2016 Feb 16;114(4):454-62. doi: 10.1038/ bjc.2015.472.

21. Beukers W, van der Keur KA, Kandimalla R, et al. FGFR3, TERT and OTX1 as urinary biomarker combination for surveillance of bladder cancer patients in a large prospective multicenter study. J Urol. 2016 Dec 31. pii: S0022-5347(16)32099-7. doi: 10.1016/j.juro.2016.12.096.

22. Mengual L, Lozano JJ, Ingelmo-Torres M, Gazquez C, Ribal MJ, Alcaraz A. Using microRNA profiling in urine samples to develop a non-invasive test for bladder cancer. Int J Cancer. 2013 Dec 1;133(11):2631-41. doi: 10.1002/ijc.28274.

23. Chou R, Gore JL, Buckley D, et al. Urinary Biomarkers for Diagnosis of Bladder Cancer: A Systematic Review and Meta-analysis. Ann Intern Med. 2015 Dec 15;163(12):922-31. doi: 10.7326/M15-0997.

24. van Rhijn BW, van der Poel HG, van der Kwast $\mathrm{TH}$. Urine markers for bladder cancer surveillance: a systematic review. Eur Urol. 2005 Jun;47(6):736-48.

25. Kamat AM, Karam JA, Grossman HB, Kader AK, Munsell M, Dinney CP. Prospective trial to identify optimal bladder cancer surveillance protocol: reducing costs while maximizing sensitivity. BJU Int. 2011 Oct;108(7):1119-23. doi: 10.1111/j.1464-410X.2010.10026

26. Hennenlotter J, Huber S, Todenhöfer T, et al. Point-of-Care Tests for Bladder Cancer: The Influencing Role of Hematuria. Adv Urol. 2011;2011:937561. doi: 10.1155/2011/937561.

27. Raitanen MP, Kaasinen E, Lukkarinen O, et al. Finnbladder Group. Analysis of false-positive BTA STAT test results in patients followed up for bladder cancer. Urology. 2001 Apr;57(4):680-4.

28. Lüdecke G, Pilatz A, Hauptmann A, Bschleipfer T, Weidner W. Comparative analysis of sensitivity to blood in the urine for urine-based point-of-care assays (UBC rapid, NMP22 BladderChek and BTA-stat) in primary diagnosis of bladder carcinoma. Interference of blood on the results of urine-based POC tests. Anticancer Res. 2012 May;32(5):2015-8.

29. Grossman HB, Messing E, Soloway M, et al. Detection of bladder cancer using a point-of-care proteomic assay. JAMA. 2005 Feb 16;293(7):810-6.

30. Smrkolj T, Mihelič M, Sedlar A, Sterle I, Osredkar J, Sedmak B. Performance of nuclear matrix protein 22 urine marker and voided urine cytology in the detection of urinary bladder tumors. Clin Chem Lab Med. 2011 Feb;49(2):311-6. doi: 10.1515/CCLM.2011.038.

31. Ritter R, Hennenlotter J, Kühs U, et al. Evaluation of a new quantitative point-of-care test platform for urine-based detection of bladder cancer. Urol Oncol. 2014 Apr;32(3):337-44. doi: 10.1016/j.urolonc.2013.09.024.

32. Hakenberg OW, Fuessel S, Richter $\mathrm{K}$, et al. Qualitative and quantitative assessment of urinary cytokeratin 8 and 18 fragments compared with voided urine cytology in diagnosis of bladder carcinoma. Urology. 2004 Dec;64(6):1121-6.

33. Sánchez-Carbayo M, Herrero E, Megías J, Mira A, Soria F. Initial evaluation of the new urinary bladder cancer rapid test in the detection of transitional cell carcinoma of the bladder. Urology. 1999 Oct;54(4):656-61.

34. Mian C, Lodde M, Haitel A, Egarter Vigl E, Marberger M, Pycha A. Comparison of two qualitative assays, the UBC rapid test and the BTA stat test, in the diagnosis of urothelial cell carcinoma of the bladder. Urology. 2000 Aug 1;56(2):228-31 
35. Babjuk M, Kostírová M, Mudra K, et al. Qualitative and quantitative detection of urinary human complement factor H-related protein (BTA stat and BTA TRAK) and fragments of cytokeratins 8, 18 (UBC rapid and UBC IRMA) as markers for transitional cell carcinoma of the bladder. Eur Urol. 2002 Jan;41(1):34-9.

36. Ecke TH, Arndt C, Stephan C, et al. Preliminary Results of a Multicentre Study of the UBC Rapid Test for Detection of Urinary Bladder Cancer. Anticancer Res. 2015 May;35(5):2651-5.

37. Horstmann M, Patschan O, Hennenlotter J, Senger E, Feil G, Stenzl A. Combinations of urine-based tumour markers in bladder cancer surveillance. Scand J Urol Nephrol. 2009;43(6):461-6. doi: 10.3109/00365590903296837.

38. Todenhöfer $\mathrm{T}$, Hennenlotter J, Esser $\mathrm{M}$, et al. Combined application of cytology and molecular urine markers to improve the detection of urothelial carcinoma. Cancer Cytopathol. 2013 May;121(5):252-60. doi: 10.1002/cncy.21247. 